\title{
COST ESTIMATING - MAKE OR BUY? ${ }^{1}$
}

\begin{abstract}
Determining how a corporate real estate organization estimated its project costs was a big decision that impacted budgets, customers, and the bottom line. What recommendations should be made for improvement of cost estimating at our upcoming management meeting?
\end{abstract}

Troy Montgomery, a consultant at Humana in April of 2015, was tasked with providing leaders of Humana's corporate real estate group, Workplace Solutions (WPS), with an answer as to how to provide early cost estimates on large construction projects. Should they create a solution internally, outsource development of a solution, or look to an existing solution to provide a "cost calculator"? There was so much variation in the types of projects WPS worked on, not to mention an assortment of internal clients they served. Such complexity made it virtually impossible to come to a straight forward recommendation.

Humana was a leading health and well-being company focused on making it easy for people to achieve their best health with clinical excellence through coordinated care. When Humana needed a new or renovated office building, call center, pharmacy, or medical center they engaged the WPS team to manage the start to finish solution. Similar to any other large project, the end user was concerned with three things: time, cost, and quality. The initial questions from WPS internal clients were typically "How long is this project going to take and how much will it cost?” WPS managers believed they provided sufficient cost estimates once all of the planning activities were completed, contracts selected, and construction drawings finalized. However, they were curious to know if they could provide better estimates at the initial onset of a new project, before all of the planning was complete.

In late 2014 and early 2015 Montgomery led a small, cross-functional team of WPS associates through process improvement initiatives. The team had only been commissioned for six months, and due to their success, WPS leaders challenged the team to identify additional improvement opportunities. Determining a solution to an issue like cost estimating would not only build the credibility of Montgomery's team, but it would also open up new opportunities for additional improvements in the future.

First, the team identified the current methodology for cost estimating within WPS. In parallel they researched cost estimating tools on the market and investigated best practices within the industry. Based on the team's analysis, WPS leaders recognized they needed a solution in a short period of time. Should they task internal resources, purchase an out-of-the-box IT tool, or commission an external vendor to create a solution?

\footnotetext{
${ }^{1}$ Copyright (C) 2017, Troy Montgomery. This case was prepared for the purpose of class discussion, and not to illustrate the effective or ineffective handling of an administrative situation. Names and some information have been disguised. This case is published under a Creative Commons BY-NC license. Permission is granted to copy and distribute this case for non-commercial purposes, in both printed and electronic formats.
} 


\section{Healthcare}

As Bruce Broussard, CEO of Humana Inc. said, "Healthcare is a mess and we are all to blame!" (Osborn, 2015). The healthcare system in the U.S. was one of the most complex healthcare structures in the world and accounted for close to three trillion dollars of annual spend in 2014 (Jonas, Goldsteen, \& Goldsteen, 2013). In its simplest terms, the system could be broken into five major components: facilities, workforce, suppliers of therapeutics, education and research, and financing mechanisms (Jonas et al., 2013). Refer to Exhibit 1 for additional details on the major components of healthcare.

\section{Medical Insurance and the Competitive Landscape}

Private medical insurance was primarily provided to individuals through a plan sponsored by their employers, but could also be purchased through retail channels by individuals. Employers and/or individual consumers paid a prescribed amount of money, known as the premium, to the insurance company. Employers provided health insurance as a benefit to their employees and paid a large percentage of the premium. The insurance company then agreed to provide reimbursement for all, or a portion of, the contracted medical services for a specified beneficiary (the individual). Services were generally provided by a hospital or a clinic. Examples of services included annual physicals, acute care visits, emergency room (ER) visits, subspecialist visits, procedures, laboratories, and pharmaceuticals.

Public health insurance consisted primarily of Medicare, Medicaid, and Children's Health Insurance Program (CHIP). These were government sponsored programs aimed at providing U.S. citizens who could not afford private insurance with quality medical benefits. Individuals qualified for government healthcare benefits based on age, income, and/or other specific criteria. Medicare and Medicaid worked in a similar fashion to private insurance. However, the federal or state government would provide the hospital or clinic the subsidies to fund specific medical services on behalf of the beneficiary.

Insurance companies provided many types of products including HMO plans, PPO plans, POS plans, and high deductible plans. Each plan was a contract between the consumer (also known as the member) and the insurance company (also known as the "payer") that stated what services were covered.

\section{Changes to Regulations}

After the Affordable Care Act (ACA) was signed into law by President Barak Obama in 2010, healthcare in the United States underwent a significant amount of change. The ACA was intended to increase the number of Americans who were covered by insurance (private or public) while decreasing healthcare costs. This massive overhaul of the healthcare system resulted in reforms and new regulations affecting health insurers, healthcare providers, and patients. Due to the multi-phase roll out of the ACA, it was difficult for companies to foresee future impacts of the reforms.

Health insurance companies were projected to grow due to the generation of new members with the introduction due to ACA. A projected annualized revenue growth rate over five years of $3.1 \%$ to $\$ 852$ billion in 2020 was expected (Hoopes, 2015). However, profit margins, which were already tight at 5\% for medical insurance companies compared to $17.4 \%$ for all other industries, were expected to decline due to lower reimbursement rates for government sponsored plans (see Exhibit 2 for revenue and margin projections) (Hoopes, 2015). The medical insurance market had become more concentrated through recent mergers and acquisitions. This concentration was most likely due to the general complexities in healthcare and the potential for companies to increase their margin through economies of scale. The largest four companies accounted for close to $38 \%$ of revenue in 2010 and were closer to $46 \%$ in early 2015 (Hoopes, 2015). UnitedHealthcare, Aetna, Anthem, and Humana made up the largest medical insurance companies in the U.S. 


\section{Humana Inc.}

"We are an insurance company, but we are in the business of improving health outcomes and simplifying the process.” - Bruce Broussard, CEO of Humana Inc.

Humana, headquartered in Louisville, KY, was one of the largest health and well-being companies in the U.S. serving over 14 million members through medical benefit plans and 7.4 million members in specialty products. The company was founded in 1961 and employed approximately 57,000 associates as of December 31, 2014. They enjoyed significant growth over five years that started with revenues of $\$ 33.6$ billion in 2010 and increased to $\$ 48.5$ billion in 2014 (see Exhibit 3). Its primary source of revenue came from providing medical insurance to members through their Medicare Advantage (MA) product. A Medicare Advantage plan was simply a Medicare insurance plan offered through a private company to Americans aged 65+ or to individuals that met criteria created by the Centers for Medicare \& Medicaid Services (CMS).

Humana embraced an integrated care delivery model (see Exhibit 4) that made it easy to achieve health through clinical capabilities. In 2015 the company rolled out the Humana 2020 goal: "The communities we serve will be 20 percent healthier by 2020 because we make it easy for people to achieve their best health.” It increasingly sought to create innovative ways to provide preventative healthcare services. This shift in moving from an insurance company to a health and well-being company was brought to life through recent acquisitions and growth in new services. Starting in the mid 2000's Humana continued to build affiliated partnerships with primary care physicians (PCP) and began to acquire a number of primary care clinics. Examples included MetCare, Continucare, and CAC in the state of Florida. In 2006 Humana launched RightSourceRx ${ }^{\circledR}$, a pharmacy solution that provided mail-order prescription services for brand, generic, and specialty drugs, and diabetic supplies.

Humana grew its home-based services by acquiring Senior Bridge in 2012 and American Eldercare in 2013. This Humana At Home business provided preventive care and other healthcare services for Humana members. Examples included phone based preventive care, in-home nursing services, and innovative in-home healthcare monitoring. In March of 2015 Humana launched Transcend and Transcend Insights companies with the goal of helping healthcare systems, physicians, and care teams transition from fee-for-service to value-based reimbursement models. Transcend provided resources in care coordination and financial risk management, on-site training, and data analytics to collaborate with physicians to improve patient engagement and improved health outcomes.

\section{Workplace Solutions (WPS)}

\section{Overview}

Within Humana, the Workplace Solutions organization provided services that supported Humana's real estate portfolio and workplace needs. Services provided included commercial real estate planning, lease administration, construction management, workplace vendor management, and day-to-day facilities management.

In 2014, WPS managed the planning and execution of 200 workspace projects with a budget close to \$200 million. Each year the volume, size, and overall demand of these projects had increased. Projects varied and included new construction, major and minor renovations, and decommissioning of existing facilities. It also included simpler solutions such as carpet, paint, and equipment updates. The requesting 
Humana department (internal client to WPS) would develop the business case for a new project, work with WPS to develop financials to include in the budget, and partner with WPS to create the requirements for the project. WPS managed the planning, worked with real estate property owners, executed leases, managed construction vendors, provided on going day to day facilities support, and provided occupancy cost allocations.

All facility related costs were charged back to the line of business using a simple allocation method based on the percentage of space a group occupied. For example, in several administrative office buildings there were a mix of Humana associates from different business groups. If the "Retail group" occupied $60 \%$ of the square feet in a building and the "Employer group" occupied the remaining 40\%, the total building costs would be allocated using a 60/40 split between the two groups.

\section{Adapting to a New Model}

WPS supported more than 600 facilities across 42 states with close to 9 million square feet under management. The growth of Humana presented a particular challenge to the WPS team of close to 90 associates. When Humana was primarily a medical insurance company, the work space utilized by associates was relatively consistent. The majority of the owned or leased facilities consisted of commercial office buildings intended for administrative staff, sales teams, or call center personnel. The recent shift to a health and well-being company brought the need for new types of facilities to serve a variety of business needs.

\section{Facility (Asset) Types}

On a typical work day in 2015, a real estate WPS associate conducted a strategic search for retail space in a shopping center to support a new 4,000 square foot "Guidance Center" to serve as wellness space for a variety of activities and education for both Medicare members and non-members. Another WPS project manager visited the site of a four-story medical center ground up build for a primary care and specialty care clinic. A third WPS associate worked with a property owner to lease additional space for a pharmacy distribution center that packages and ships prescriptions directly to members. These are just a few of the different asset types WPS would deal with on a daily basis. See Exhibit 5 for a generic list of asset types.

\section{WPS Organization Structure}

WPS had recently undergone organizational change. In 2012 the organization moved from a decentralized model to the more centralized shared service model as illustrated in Exhibit 6. Prior to 2012 each line of business had a WPS Associate Engagement Leader (AEL) who quarterbacked all WPS functions--from construction to lease negations and facility management. Each AEL had a team of associates that were aligned to one Humana line of business leaders.

This model had its limitations as Humana grew both organically and through acquisition. In 2012 leadership moved to a centralized shared service model. Associates were grouped into five key functional areas with a manager leading each team. Additionally, three large vendors were contracted to serve as construction project managers, transaction managers, and on the ground facility management technicians.

It became apparent that Humana business lines, and WPS associates, were not always clear on when, how, and who was responsible throughout a typical WPS construction project.

"In the first year following the centralization of services, there was a great deal of scope confusion across the new process areas. We spent much of the first year ironing out which group was responsible for each unique task. Many operational conversations started with 'Who is responsible for...'” said Brad Keller, WPS Consultancy Manager. 
In early 2014, the managers agreed there was a clear need to reduce confusion among WPS associates, increase accountability, and provide internal clients with an improved level of service.

"As leaders, we could not give the process change efforts the dedicated time it required to be successful. Conversely, we did not have time to locate and fund internal or external consulting resources to drive the required changes. Instead, it was determined that the quickest course of action would be to repurpose existing internal resources to lead the change efforts," said Keller.

\section{The PIT Crew}

In June 2014, the Process Improvement Team (PIT Crew) was formed. A cross-functional team of WPS associates were empowered to identify, prioritize, and execute improvements focused on delivery of construction projects. Montgomery, a new associate with prior management consulting experience, was asked to lead the team of five, one from each WPS functional group. Each of the team members maintained most of their previous workload and allotted 20\% of their time to the PIT Crew over the next six months.

WPS leaders strategically selected the team members to provide an example of what could be accomplished by a remote team as well as giving them an opportunity to participate in a stretch assignment. All of the team members were relatively new to Humana and all worked outside of the Louisville headquarters. All team members intermixed their days in a local Humana office, their home office, or wherever their business travels took them that day.

To kick-off the PIT Crew initiative, 40 WPS associates were asked to participate in a 1 1/2 day "table top" exercise. The associates were divided into three teams, mixing functional expertise. Each team was given a case study that consisted of a large existing project from a different internal business partner. The teams were tasked with outlining an approach on how to handle the project from start to finish and document the recommended steps along the way. Each team identified challenges and opportunities for WPS. Upon compilation of all ideas, the teams shared their findings in a broader group discussion.

The exercise was unique due to the use of Video Technology Conferencing (VTC). This allowed associates located in a conference room in Miami, FL to view live video of associates in a conference room in the Louisville, KY headquarters, a conference room of associates in Phoenix, AZ, and other associates working from home via their laptop cameras. The technology eliminated the cost of travel, minimized productivity loss due to travel, and created a more fluid conversation among team members compared to a conference call.

Between the table top exercise and a broad set of interviews across WPS, the PIT Crew had identified a plethora of improvement opportunities. There were re-occurring discussions about the need for standardization of processes, and the desire for an IT system to integrate the work. WPS utilized an IBM system called Tririga that housed real estate data including leases and associated transaction information. They also utilized a home-grown Microsoft SharePoint site to intake new projects, apply resources, and house several internal project documents. Financial data including budgeting information and actual spend was kept in the corporate ORACLE system.

Over 100 ideas were documented, reviewed, and then categorized into execution buckets by the PIT Crew. In order to divide the work into manageable chunks, the team labeled ideas as quick wins (able to be completed within 30 days), phase 1 projects (completed within the next three to six months), or as later 
phase projects (more than six months to complete or requiring additional resources). Most of the quick wins and early work was focused on minimizing process variances and defining how construction projects were delivered.

During Q3 and Q4 of 2014 the PIT Crew worked diligently to gather best practices. Associates adapted to new project types as Humana continued to grow. They came up with new methods and tools to complete construction projects. However, these improvements remained with the individuals on their laptops and were not shared across WPS. The PIT Crew provided a way to gather the best of the best from associates and begin to broadcast new ways to solve older problems.

Quick wins were rolled out within the first month providing credibility for the team. Later, tools and templates were created to assist in analyzing information, and providing internal Humana customers with the data that was needed to improve planning. A standardized process for delivering construction projects was developed and reviewed collaboratively among all WPS associates. Project phases and milestones enabled a structure for future measurement of time and clearer communication on progress to business partners. All the work was done in a cross-functional manner. Each of the five functional WPS groups had a voice through a representative on the PIT Crew. As changes were developed, the PIT Crew used existing functional group meetings to communicate findings and solicit feedback on changes.

\section{PIT Crew Phase 2}

Managers and associates seemed to agree that the PIT Crew model proved to be a success in 2014. Then 2015 brought the challenge of implementing the changes and engraining them into associate's behavior. Additionally, early in 2015 WPS management was able to secure funding approval for a new Integrated Workflow Management System (IWMS). The IWMS system implementation brought the prospect of creating one integrated system for projects, real estate data, space management information, and financial allocations. The PIT Crew facilitated process changes and IWMS would be able to automate those changes. It was an exciting time in WPS, as improvements were made in the short term with the prospect of a new system integration implementation in mid-2016.

In order to continue the momentum, the PIT Crew needed to identify new initiatives for the next round of prospective improvements. One topic not addressed in the first phase of work included how costs were estimated for large, capital intensive projects. Cost estimation improvements were not in the scope of the IWMS integration work and required attention. Keller and the WPS management team asked for more information on the subject. The key issues and potential solutions related to cost estimation were not clear. The PIT Crew needed to provide this information along with a recommendation for their next WPS management meeting.

\section{Cost Estimating}

In project management literature, the triple constraint is illustrated as a triangle made up of time, cost, and quality (see Exhibit 7). Projects must be delivered on time, within a specified cost, and in a manner that is considered acceptable to the end user. Consultants and project management gurus professed clever sayings such as "time, cost, and quality, pick any two!" It was extremely difficult to attain a high-level outcome for all three constraints in one project. High quality generally would cost more. Expediting the time required to complete a project would require increased cost. Likewise, cutting costs might result in less than desirable quality or an extended timeline. It was important that all three constraints were addressed, prioritized, and measured for a successful project.

Cost estimations were only as good as the confidence in the information and data available. For example, providing a cost estimate for a new sports car based only on a conceptual drawing would prove to be 
exponentially more difficult than estimating the cost of making incremental changes to the new model of an already existing SUV. In the case of the sports car all that was known was a concept in a drawing. The number of parts, materials, suppliers, manufacturing equipment, and labor needs, just to name a few, were unknowns. In contrast, the SUV model change would entail far fewer unknowns. The manufacturer was likely to utilize the existing suppliers, parts, equipment, and labor. The confidence, measured in percentage $+/-$, in a cost estimate for the sports car would have a much higher value than the model change in the SUV.

In the case of WPS, until a full set of requirements (or parameters) were established it was difficult to predict with any certainty the confidence in a cost estimate. For example, when leasing a new facility some of the key parameters included the location (state, city, etc.), primary use of the space (retail, office, call center), the number of square feet required, and type of space required (class A or B commercial space or shopping center retail space). Once the detailed requirements are defined the potential cost estimate becomes slightly clearer. The exact location for the leased space, the property owner's price, the necessary renovations, or the cost of labor remained as unknown. When a facility site was located, construction drawings must be completed and contractors must bid on the work. This was a simplified example that illustrated the different layers of information over time that improved the confidence and ability to estimate costs (see Exhibit 8).

Historical data was a critical factor that contributed to the confidence in an estimate. When a similar project has been completed, theoretically there should be historical data available to serve as a baseline. It was much easier to use baseline costs with adjustments, like the SUV model example above.

\section{Cost Estimating in WPS}

For WPS projects cost estimation happened in 3 different phases: annual budgeting, in flight projects, and tracking actual spend (see Exhibit 9). Annual budgeting consisted of a back and forth discussion with business leaders over a period of a few months. WPS worked to understand business strategy and identify projects that could support that strategy in the following fiscal year. Budgeting started in Q3 of the prior year and concluded in Q4. The project scope was typically very rough and subject to change prior to the project actually starting. For example, a business leader may estimate the need for 4 new medical clinics for the ensuing year. The general region may be known, but the exact location was unknown. Because of the lead time in annual budgeting, it was difficult to project the number of members each clinic would serve, thus impacting the square foot estimates. Additionally, the breakdown of cost estimates so early in the project life cycle consisted of only three categories: WPS capital (construction, material, and labor), Furniture, and IT. It was a very high level estimate.

Once a project kicked off, which could be months after the annual budget plan was approved, the detailed requirements were developed. The WPS team worked closely with the business in coming up with the exact number of offices, cubes, conference rooms, and other unique parameters that were needed to provide associates with the most efficient workspace. A market survey was completed to locate the best available site in the state and city specified. Architecture partners were brought in to assess the space and provide initial floor plan layouts. Once the conceptual floor plans were finished WPS worked to provide the business partners with a cost estimate. These estimates included a more detailed list of line items compared to the three from the annual budget. The cost was derived from several sources (see Exhibit 10). The highest percentage of costs came from construction and furniture (see Exhibit 11). Construction costs were estimated by utilizing a $3^{\text {rd }}$ party General Contractor (GC). The GCs were not yet under contract with Humana for the project, and this was not the official bidding process to gain contracted 
work. The GCs were simply asked to provide an estimate for construction costs based on requirements gathered and general floor plans created.

WPS consolidated costs and presented the business leaders with the amount in capital, as well as an allocated monthly operating expense estimate. Business leaders with the proper approval authority decided to move the project forward, cancel the project, or ask for a decrease in cost (usually resulting in a scope change). If a project was cancelled, a significant amount of work and time was lost. Limited resources were utilized to gather requirements, identify a site, and develop conceptual floor plans. When the scope changed, some, or all of the work, would need to be revisited. It was critical for business leaders to understand the ballpark cost of a project before significant time and resources were exerted.

"Cost estimating is a delicate balance between providing enough cushion to avoid unforeseen overages and presenting business partners with reasonable numbers. Without precision in cost estimating, it often requires either going back to the well for more funds or chasing down your business partner before they run away from the original estimate too quickly," said Keller.

Assuming the business leader approved the costs to move forward, WPS would then begin developing the full construction drawing exercise and bid out the construction work to contractors. Project managers would gather the "bid" costs and work with Procurement to develop purchase orders (POs) and contracts for the winning vendors. These bid estimates were the most accurate estimates and what PO's were based on.

Tracking actual costs was another important aspect of cost estimation. The system of record for incurred project expense was the corporate ORACLE system. The project management team would track actual costs against cost estimates in Tririga (see Exhibit 6). While the Tririga financial categories and ORACLE financial categories were similar, they were not a one for one match. Therefore, reports in Tririga for project variances could be slightly different for a particular category compared to ORACLE.

\section{General Contractor Bidding}

For most projects Humana would use an architecture and engineering (A\&E) firm to first complete the design. Next they would bid the construction work out to at least 3 GCs in order to gain the best available price. The GC was in charge of completing the actual construction based on the design plan from the A\&E firm. In a few instances, work was awarded to a pre-selected GC based on previous experience. Most projects were bid to 3 or more GCs once the planning was completed.

In the construction industry the process of utilizing an A\&E firm to plan the design and then bid the construction out to a GC was known as Design/Bid/Build. A second methodology involved contracting with a GC at the start of the project and awarding them the project work at the project onset. The GC was in charge of both the design and construction aspects of the project. This was known as Design/Build (see Exhibit 12). Design/Build was not typical at Humana and required a significant amount of partnership with Humana procurement. Developing a contract for a Design/Build project was critical in mitigating risk up front as well as ensuring the right GC was selected. The payoff in time saves and cost reduction could be big. However, there was also less control in creating and changing the design. This type of structure would be best fit on projects where the design was clear. For example, some new medical centers were designed to be "cookie cutter" solutions. This was comparable to a national retail chain that used the exact same store design for all stores.

GCs that completed multiple Humana projects began to build a trusted relationship. These GCs became familiar with the standards and expectations that come with a Humana project. They were able to anticipate needs and foresee risks before they became an issue. Procurement developed a list of preferred 
GCs so future projects could take advantage of these formed relationships. It was easier to obtain trusted cost estimates for projects when using a preferred GC. However, some projects did not allow for a preferred GC. Humana had instances where they planned to move into a different market or build a new type of facility (i.e., a medical center or pharmacy) in an existing market. WPS was able to utilize a national GC to provide estimates in some of those cases. In other cases, there were no relationships established with a preferred GC. This proved difficult in gathering cost data since a new GC would not have an established relationship with Humana and was unfamiliar with Humana projects.

\section{Market Tools \& Outside Vendors}

Based on the current methodology and state for WPS cost estimating, the PIT Crew researched other options available outside of Humana. A number of subscription based tools seemed to provide accurate cost estimates for corporate real estate construction. RSMeans was an industry recognized source used to provide detailed cost estimates based on factors including the type of materials down to the number of fasteners (see Exhibit 13). This tool was primarily targeted for GCs to use in creating bids.

Constant data updates were the key advantage in using an external source for construction estimates. Material prices fluctuated based on market forces. Construction labor costs were different in regions with stronger unions. As the prices changed due to market conditions, it was very difficult to maintain an internal database that reflected up to date cost estimates. While the subscription based tools provided general construction costs, they did not take into account specific Humana standards.

A real estate consulting firm in Tampa, FL, discussed a customized solution with PIT Crew members. They had developed similar cost estimating tools that were SQL, Excel, or Access based. The tools were able to integrate with existing internal systems of other clients. In addition to having the expertise in building customized solutions, the firm had a good pulse on what other similar organizations in the industry were doing for cost estimating.

"We didn't believe Humana would be pleased with an off the shelf product based on the complexity of their business needs. We had helped similar large corporate real estate organizations construct a tool that integrates multiple sources to estimate costs using historical company project data and accounting for changes in the market and regional variances." - Managing Director of Consulting Firm.

The consulting firm was agreeable to provide a pro-bono brain storming session to present potential solutions to WPS. There was no budget currently in place, however, all agreed that if the benefits justified the costs then funds could be procured.

\section{Moving Forward}

In April of 2015, WPS announced a new Workplace Solutions Leader would be starting in the next week as an external hire. The previous leader had accepted a different role internal to Humana. The new leader had deep corporate real estate experience as an account lead in one of the largest real estate services and brokerage firms in the U.S. The firm had specialized in providing an entire suite of corporate real estate services to large organizations like Humana.

Considering all of the complex factors involved, it was clear to Montgomery and the PIT Crew, there were opportunities for improvement. How would new leadership impact, if at all, the recommendations the team would present. What was the best alternative given all of the circumstances? 


\section{Utilize Historical Data and Build a Cost Estimation Tool in House}

Building a tool in house would have been the most cost efficient as well as kept all control of the data and solutions internal to Humana. This would ensure that historical data was used as the foundation and core to future cost estimates. Humana standards and past practices would be considered properly.

In order to undertake this option, WPS must assign a resource or resources who could develop a tool. There were a few individuals who were capable of taking on this task. They were well versed in building complicated programs in Excel and Access, but were not as familiar with other platforms or integrating systems together. In order to utilize internal resources, it would have required some major shifting of people and projects. WPS managers could either move this up in priority or agree that the time to complete the cost estimation build would take much longer.

\section{Utilize Historical Data and Outsource the Build of a Cost Estimation Tool Build}

Similar to the first option, this would ensure that Humana historical information was the basis for estimating costs. Utilizing external resources, like the real estate consulting firm, would allow for minimal disruption to existing workloads as well as gaining an outside perspective on systems and platforms to be used. WPS would be able to hold the external resources to a specific timeline, and choose the requirements necessary to develop a cost estimation tool.

On the other hand, allowing a $3^{\text {rd }}$ party vendor to build a solution could make future changes and maintenance more difficult. WPS would potentially have to rely on the vendor to make any adjustments. There would be a cost to this build, and PIT Crew did not yet have a formal budget. There were initial discussions with managers with agreement that they would be open to potential spend if properly justified.

\section{Purchase a Cost Estimating Solution}

From the research on existing available subscription based products, it didn't seem that this was a viable solution by itself. The best part about the available estimators online was the constant updating of material prices and labor. However, the details for early project estimations didn't make sense. At the budgeting and early cost estimating phases, there was virtually no way to determine the parts and materials that would be required for a site not yet selected.

Was it possible to integrate indexes from an existing solution for material and labor fluctuations to a customized cost estimation tool built in house or by a vendor? These seemed like something to consider.

\section{Design/Build vs. Design/Bid/Build}

The PIT Crew heard from both internal associates and external associates that large organizations were increasingly utilizing Design/Build methodology. Based on the advantages and disadvantages should WPS consider moving all projects to Design/Build, some projects to Design/Build, or simply continue as usual (see Exhibit 11)?

With so many different facility types and growing lines of business, it made it difficult to determine the appropriate recommendation. The PIT Crew was only a few days away from meeting the new WPS lead and presenting their findings to the WPS management team and thus needed to agree on what approach to take.

Should the PIT Crew recommend using internal resources to develop a cost estimating tool based on historical project data or should they look to use an external vendor to build the tool? How could they determine more accurate costs earlier in the project development? Were there opportunities to change 
other factors, such as Design/Build vs. Design/Bid/Build that could improve the overall cost estimations? The PIT Crew had a big task in front of them, and Montgomery needed to solidify their recommendations for future implementation.

\section{References}

Hoopes, S. (2015) IBISWorld industry report 52411b: Health \& medical insurance in the US. Retrieved from http://www.ibisworld.com/industry/default.aspx?indid=1324

Jonas, S., Goldsteen, R. L., \& Goldsteen, K. (2013). Jonas' introduction to the US health care system. $\left(7^{\text {th }}\right.$ ed.). New York: Springer Publishing Company.

Osborn, J. (2015). Humana’s Bruce Broussard at industry confab: Healthcare is a mess and we are all to blame. Forbes. Retrieved from http://www.forbes.com/sites/johnosborn/2015/04/15/humanasbruce-broussard-himss15-confab-healthcare-is-a-mess-and-we-are-all-to-blame/

\section{Biography}

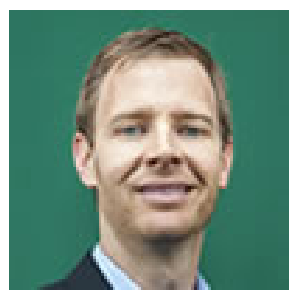

Troy Montgomery is an organization and process improvement specialist focused on identifying opportunities, solving problems, and working with managers to implement solutions for change. Troy is currently a consultant at Humana and previously served as a management consultant with a global operations consulting firm based in New York City. He started his career in engineering at GE before spending more than 3 years as an internal consultant at Bank of America.

Troy graduated with honors from the University of Notre Dame, where he earned a Bachelor's in Mechanical Engineering. He finished top of his MBA class at the University of Georgia and expects to earn his Doctorate degree in Business Administration (DBA) from the University of South Florida in December, 2017. Troy is a certified Six Sigma Black Belt and Project Management Professional (PMP). 


\section{Exhibit 1: US Healthcare 5 Major Components (Adapted from Goldsteen) ${ }^{2}$}

\section{Facilities}

The types of facilities in the healthcare system included hospitals, primary care and specialty clinics, urgent care centers, pharmacies and nursing homes (and other long term care institutions). There were more than 5,000 hospitals across the US that provided services such as pediatrics, obstetrics and gynecology, internal medicine, emergency care, and surgery. Primary and specialty care services were typically handled in a standalone retail clinic, a state or government funded community clinic, or a clinic associated with a larger medical center (hospital).

\section{Workforce}

In 2009 approximately 15.5 million people worked in the healthcare system. This included medical technicians, nurses, physicians, pharmacists, physical therapists, and dentists. Physicians were typically the dominant group in terms of decision making and authority. This was due in large part to the amount of education, training and licensing that were required for physicians.

\section{Suppliers of Therapeutics}

Suppliers of therapeutics were comprised of medical equipment organizations and pharmaceuticals. Equipment was made up of large diagnosis machinery, hospital and clinic furniture, laboratory equipment, and patient supplies such as sutures and braces. Pharmaceuticals included name brand and generic pharmaceutical organizations that manufacture prescription drugs and other medications.

\section{Education and Research}

Education and research organizations were relatively straightforward and consisted of institutions focused on advancing medical knowledge, training the healthcare workforce, and developing new technologies to improve practice.

\section{Financing Mechanisms}

The fifth component, financing mechanisms, was the most complex. The majority of individual healthcare financing groups were known as the "payers". The payers of medical insurance could be categorized as out-of-pocket, private health insurance, public health insurance, or other third-party programs. Private and public health insurance made up more than two thirds of all funds. Individuals without health insurance, who paid for health services or products on their own were considered out-of-pocket payers.

\footnotetext{
2 Jonas, S., Goldsteen, R. L., \& Goldsteen, K. (2013). Jonas' introduction to the US health care system. (7th ed.). New York: Springer Publishing Company.
} 
Exhibit 2: Healthcare Insurance 5 year Revenue Projections and 2015 Margin Expectations
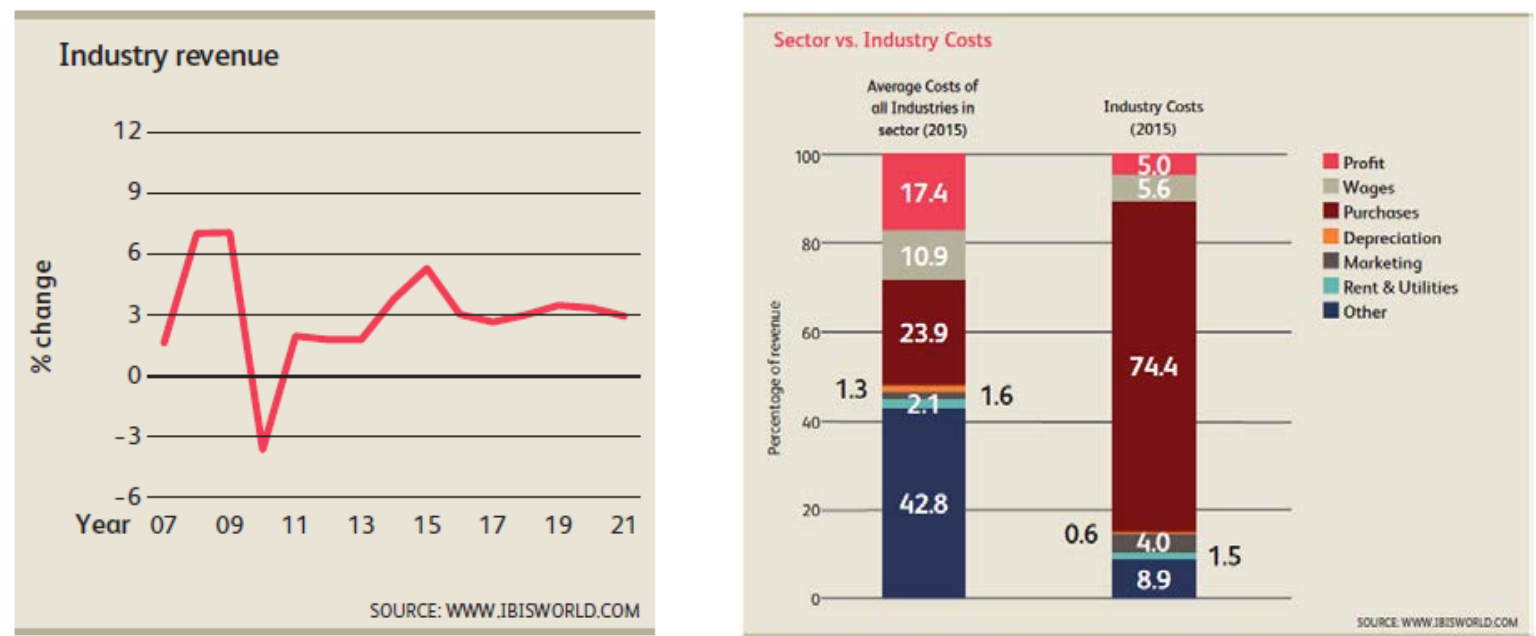

Source: http://www.ibisworld.com/ 


\section{Exhibit 3: Humana Timeline}

\begin{tabular}{|c|c|}
\hline Date & \\
\hline 1961 & $\begin{array}{l}\text { Extendicare, later renamed Humana, was founded with the building of the Heritage House nursing } \\
\text { home in Louisville, KY }\end{array}$ \\
\hline 1965 & $\begin{array}{l}\text { President Lyndon B. Johnson signs the Medicare bill into law, which provided health and long-term care } \\
\text { benefits for elderly Americans }\end{array}$ \\
\hline 1968 & $\begin{array}{l}\text { Extendicare, leveraging expanded Medicare benefits to senior citizens, becomes the largest nursing } \\
\text { home company in the United States. Extendicare purchases its first hospital }\end{array}$ \\
\hline 1972 & $\begin{array}{l}\text { Extendicare owns ten hospitals and divests out of the nursing home business. } \\
\text { Medicare benefits are extended to people with certain disabilities, regardless of age }\end{array}$ \\
\hline 1974 & Extendicare becomes Humana, focusing exclusively on managing hospitals \\
\hline 1978 & Humana grows to become the nation's number one investor-owned hospital system \\
\hline 1981 & $\begin{array}{l}\text { Humana commissions world renowned architect Michael Graves to design their headquarters building } \\
\text { in downtown Louisville. }\end{array}$ \\
\hline 1982 & $\begin{array}{l}\text { Humana strategically establishes a "Center for Excellence" program to offer Humana members specialty } \\
\text { care. This includes Humana Network providers and centers for neuroscience, diabetes, spinal injuries, } \\
\text { and artificial -heart research and surgery. }\end{array}$ \\
\hline 1984 & $\begin{array}{l}\text { The world second successful artificial heart implant is performed at Humana Hospital-Audubon in } \\
\text { Louisville, leading to Humana's founding of the Humana Heart Institute. } \\
\text { Humana launches Humana Health Plans. }\end{array}$ \\
\hline 1993 & $\begin{array}{l}\text { Humana focuses completely on healthcare insurance solutions and begins to divest out of the hospital } \\
\text { business }\end{array}$ \\
\hline 1996 & $\begin{array}{l}\text { The Health Insurance Portability and Accountability Act (HIPAA) is enacted to provide Americans with a } \\
\text { variety of protections around health insurance portability and medical privacy. }\end{array}$ \\
\hline 1997 & $\begin{array}{l}\text { The Medicare+Choice program, later renamed Medicare Advantage is enacted through Congress. This } \\
\text { program allows Medicare recipients to elect to receive their benefits through private insurers. }\end{array}$ \\
\hline 2005 & $\begin{array}{l}\text { CEO Mike McCallister initiates a focus on consumerism meaning the consumer is at the core of the } \\
\text { business }\end{array}$ \\
\hline & Medicare Part D prescription drug coverage becomes available \\
\hline 2006 & $\begin{array}{l}\text { Humana takes a lead role in education seniors about their options under Medicare Advantage and } \\
\text { Prescription Drug Plans. }\end{array}$ \\
\hline 2008 & Fortune magazine names Humana one of the top Five Most Admired Healthcare companies in the US \\
\hline 2011 & Humana celebrates 50th anniversary \\
\hline 2014 & Bruce Broussard named CEO after a 12 month transition period from Mike McCallister. \\
\hline
\end{tabular}

Source: Developed by case writer 
Exhibit 4: Humana Companies (as of 2014) and Integrated Care Model (2015)
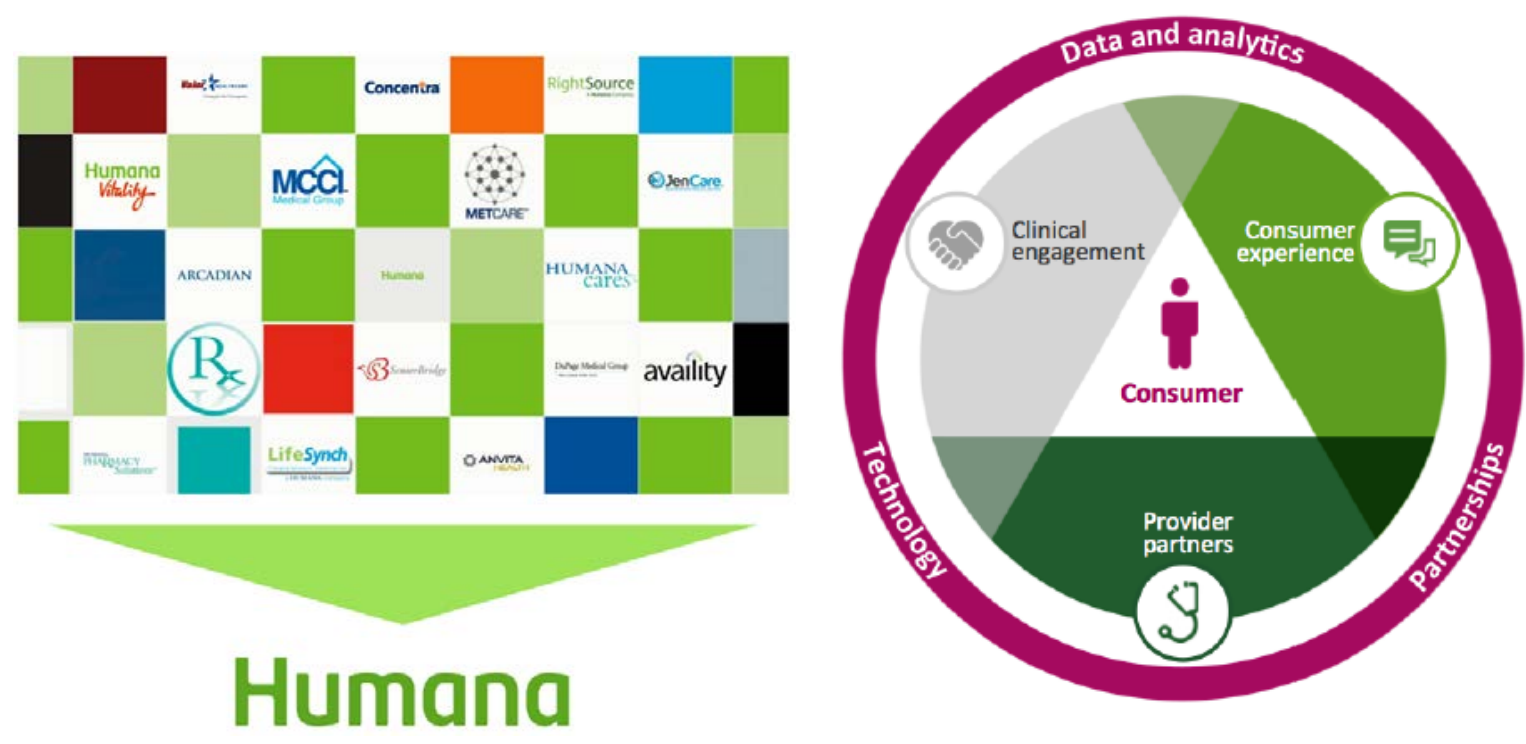

Source: https://www.humana.com/ 


\section{Exhibit 5: WPS Asset Types}

\begin{tabular}{|c|c|c|c|c|c|}
\hline Asset Type & Care Delivery & Office & Consumer & Production & Other \\
\hline \multirow{5}{*}{ 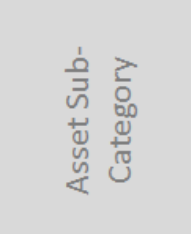 } & Clinic - Wholly Owned & Administrative & Guidance Center & Print Shop & Equipment \\
\hline & Clinic - Alliance Partner & Counseling & Sales & Distribution & Sustainability \\
\hline & Clinic - Joint Venture & Call Center & & Data Center & Aviation \\
\hline & Clinic - Ancillary Services & & & & Fitness \\
\hline & Retail Pharmacy & & & & \\
\hline
\end{tabular}

Source: Developed by case writer 


\section{Exhibit 6: Workplace Solutions Organization}

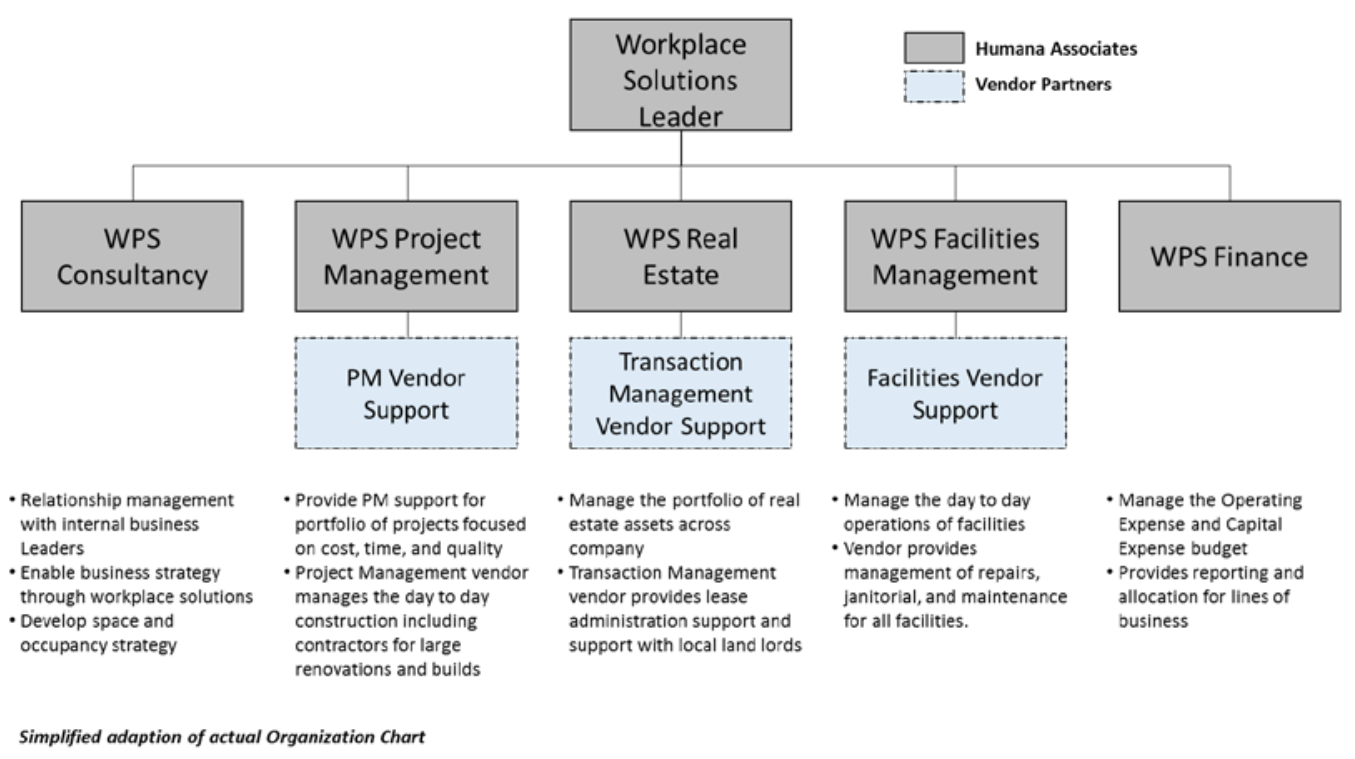

Source: Developed by case writer 


\section{Exhibit 7: Triple Constraint in Project Management}

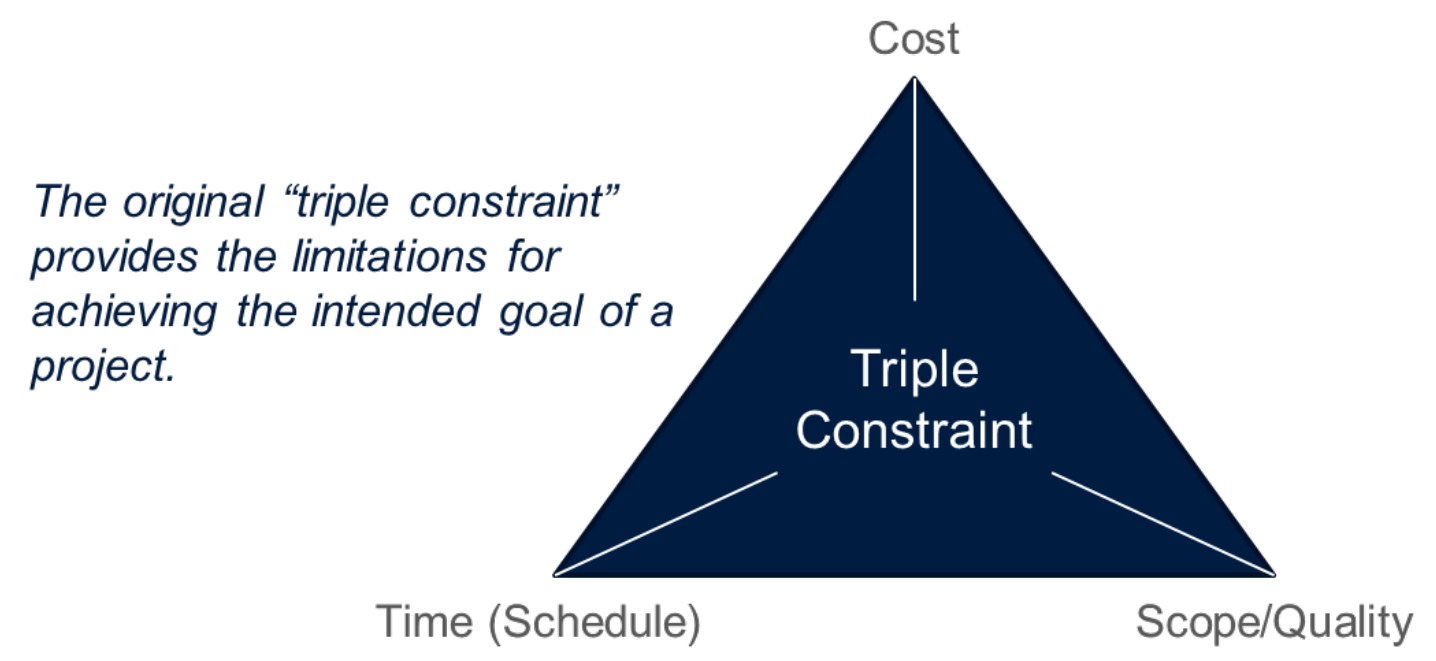

Source: Developed by case writer 


\section{Exhibit 8: Cost Estimating Process}

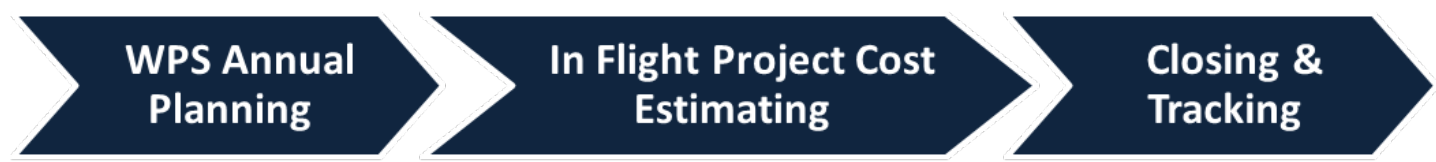

Annual planning typically occurs in Q3/Q4 of the prior year and includes both a Capital planning budget and an Operating Expense budget.
Cost estimating can occur up to 3 times once a project is kicked off:

- Rough Order of Magnitude (ROM) - occurs at initial planning phase once a project is kicked off. It can be the same as the annual planning estimates, or new information may be available to note a new estimate.

- Project Funding Approval Estimate - once planning is complete a dollar amount is approved by VP level or above business leaders

- Bid estimates - once Construction Documents are finalized these estimates are what is used to cut PO's to vendors
Financial tracking typically throughout the lifecycle of the project. Projects are financially closed a set number of days following the completion of the project.

Developed by case writer 


\section{Exhibit 9: Cost Estimation Confidence Range}

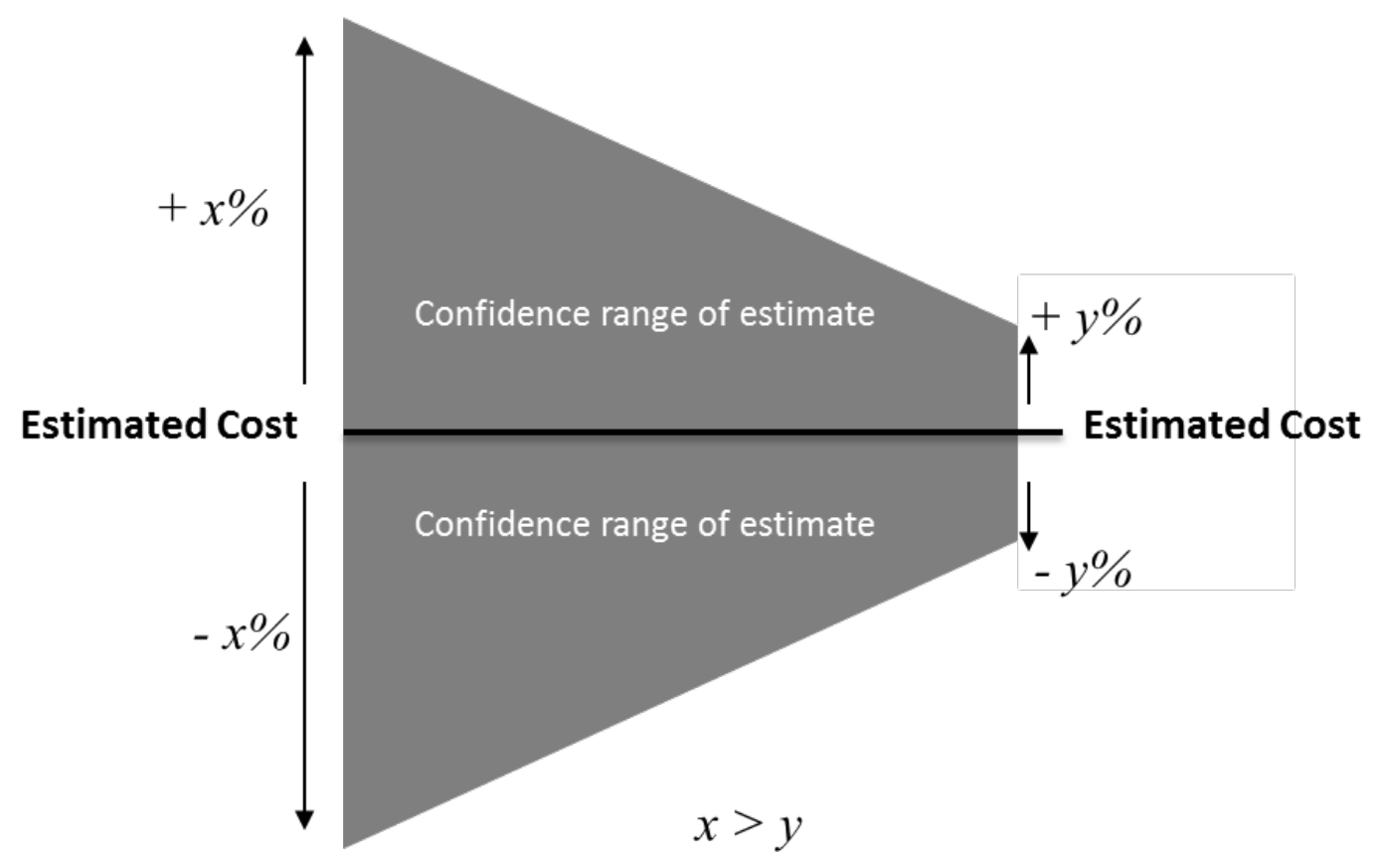

Less Information

More Information

Developed by case writer Source: 


\section{Exhibit 10: Cost Estimation Categories and Sources}

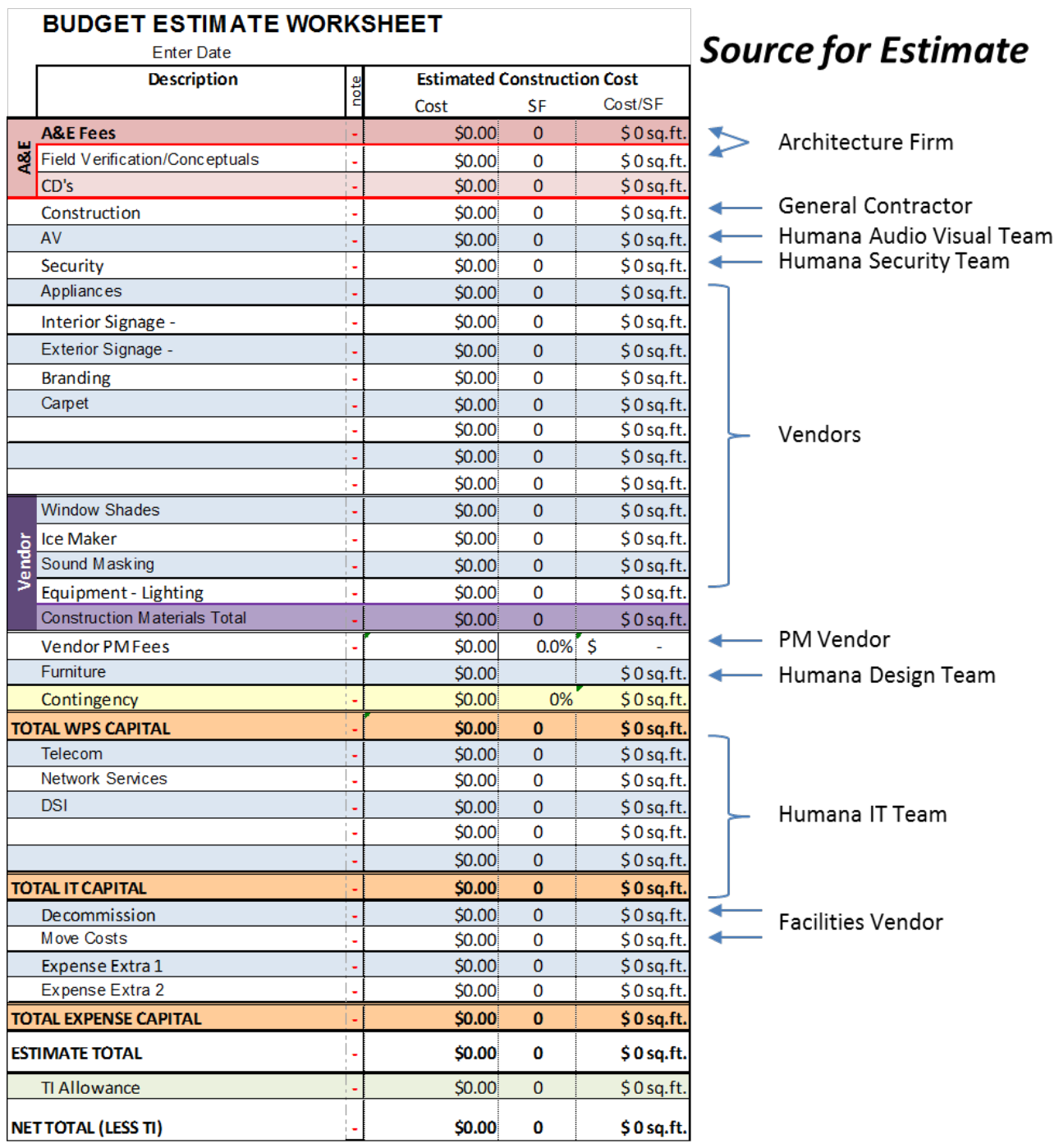

Source: Developed by case writer 


\section{Exhibit 11: Breakdown of Project Costs}

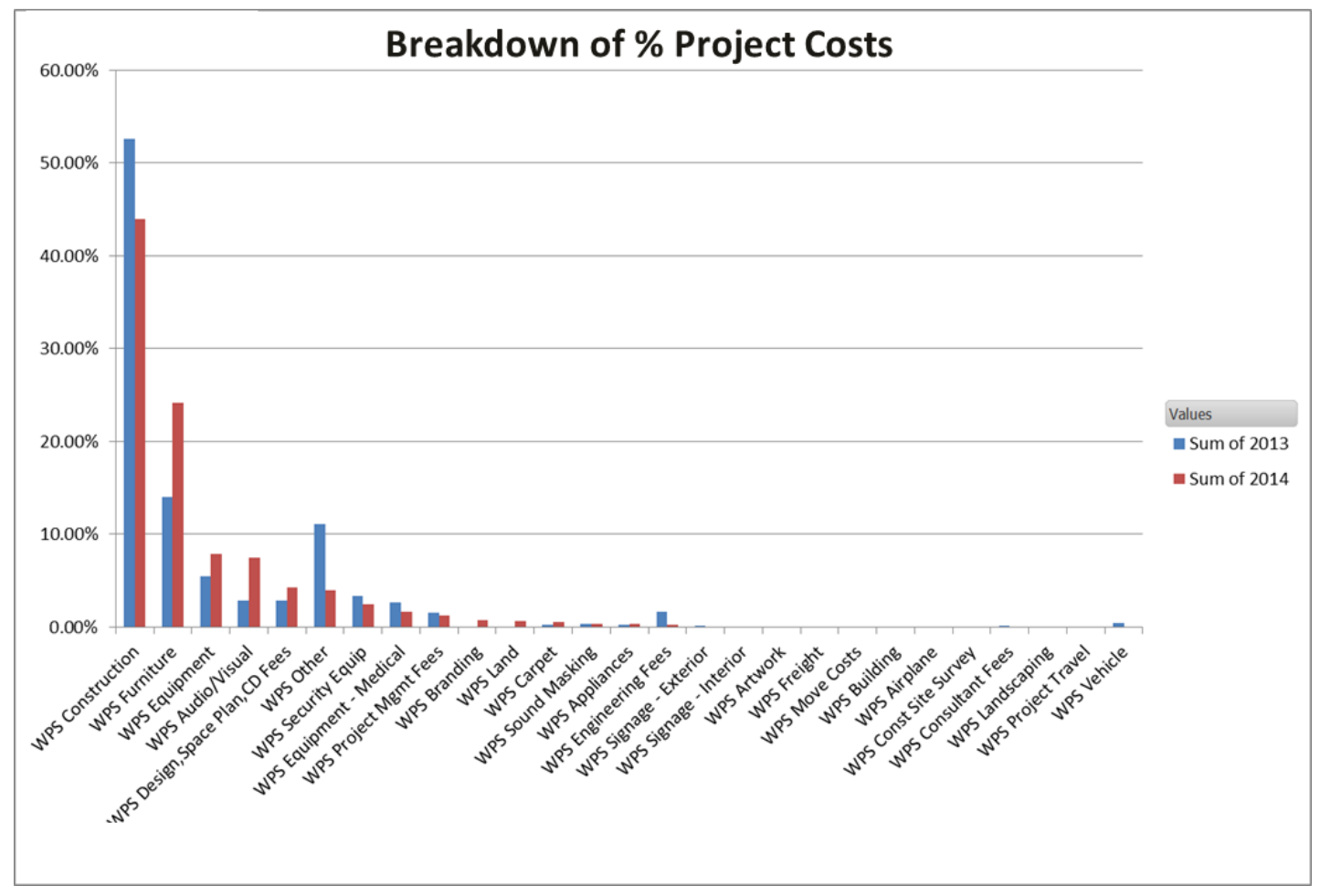

Source: Developed by case writer 


\section{Exhibit 12: Design-Bid-Build and Design-Build}

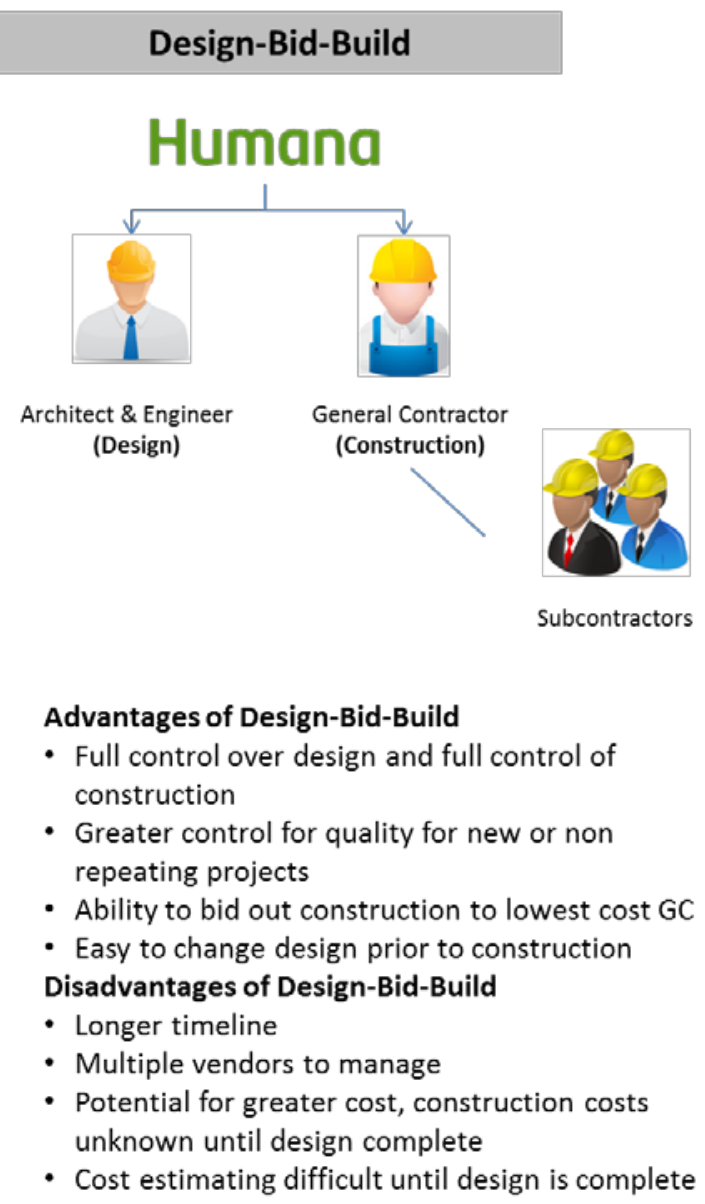

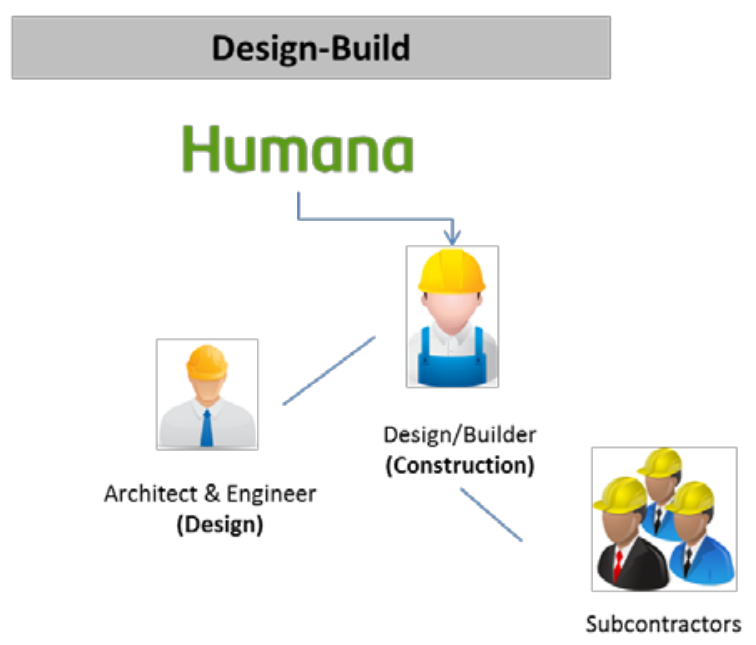

Advantages of Design-Build

- Single contact for design/construction

- Reduce risk for errors in design docs

- Reduced timeline

- Enhanced cost estimates due to early involvement of GC

- Potential for lower costs due to contractor greater control in design

Disadvantages of Design-Build

- Less control of design

- Greater definition required up front

- Incentive for GC to complete in quicker time under budget, with potential for poorer quality.

- Construction typically starts early, making design changes later expensive

Source: Developed by case writer 


\section{Exhibit 13: Subscription-Based Service}

\section{RSMeans}

FROM THE G BRDIAN GROUP:

- Gordian group owns RSMeans, who has been publishing construction costs for over 70 years

- Software and procurement processes

2. Fit for Humana Purposes

- Doesn't seem to be a good fit for a high level estimating tool

- RS Means is a construction cost data base and not necessarily a cost

3. Pros calculator

- Industry standard for construction costs

- Updated construction costs

4. Cons

Could be a "source" for a cost calculator

- Too detailed for high level estimates

- Would only include construction costs and no other costs

- Costs - \$xxx for 1 year retail subscription to cost data base

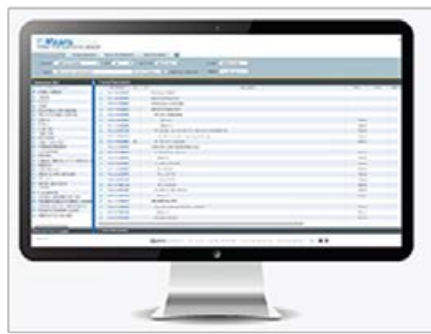

Source: https://www.rsmeans.com 